Dossiê

\title{
"É de outro planeta, ele é extraterrestre". Revisitando os estudos em Geografia da Infância no Brasil'
}

Jader Janer Moreira Lopes ${ }^{2}$

Mathusalam Pantevis Suarez ${ }^{3}$

Resumo: Este artigo tem por objetivo revisitar o campo de estudos da Geografia da Infância no Brasil e suas interfaces com outras regiões do mundo. Para isso, faz uma retomada de obras que vêm sistematizando essa área de conhecimento, assim como de textos e publicações que emergem e dialogam com essas obras. Além disso, busca atualizar alguns temas pertinentes à vida das crianças e de seus espaços geográficos, referenciados em conceitos como paisagem, território, lugar entre outros.

Palavras-chave: Crianças; Infâncias; Espaço; Geografia da Infância.

"HE IS FROM THE OTHER PLANET, HE IS EXTRATERRESTRIAL". REVISITING STUDIES OF THE CHILDHOOD GEOGRAPHY IN BRAZIL

\footnotetext{
1 Os dados citados neste artigo fazem parte da pesquisa financiada pela Fundação de Amparo da Pesquisa do Estado de Minas Gerais (FAPEMIG) que contou com bolsa da Organização dos Estados Americanos (OEA).

2 Programa de pós-Graduação em Educação - Universidade Federal de Juiz de Fora (UFJF) - Juiz de Fora - Brasil - jjanergeo@gmail.com

3 Programa de pós-Graduação em Educação - Universidade Federal de Juiz de Fora (UFJF) - Juiz de Fora - Brasil - mathusalam@gmail.com
} 
Abstract: The aim for these article is revisiting field of study in childhood geography in Brazil. For this, resumption works that come systematizing this area of knowledge, text and publications that emerge and dialog with those works. Besides that, it seeks to update some themes pertinent to children's lives and theirgeographic spaces.

\section{Keywords: Children; Childhood; Space; Geography of Childhood.}

\section{Introduç̃̃o}

Com minha chegada na sala, as crianças ficam inquietas e curiosas. A professora me apresenta, fala meu nome e de onde sou eu (Colômbia). Quando as crianças ficam sabendo que eu não sou brasileiro senão, colombiano, começam as perguntas: de onde é ele? Onde fica esse lugar? Uma das crianças responde rapidamente as questões dos outros: "é de outro planeta, ele é extraterrestre" Todas as crianças riem (...) (Nota de campo $\mathrm{n}^{\circ} .3$, 20 de maio de 2014)

A nota que abre este artigo foi produzida com crianças em uma escola situada no munícipio de Juiz de Fora, estado de Minas Gerais, localizado na região sudeste do Brasil. É um dos trabalhos mais recentes que apresenta os dados empíricos fundamentados e dialogados com o campo que temos chamado de "Geografia da Infância”.

Essa área de pesquisa tem se estruturado recentemente no Brasil, no escopo dos trabalhos envolvendo os estudos relacionados à infância e em constante interface com investigadores de diferentes origens, como a própria Sociologia da Infância, a Antropologia da Infância, a Psicologia do Desenvolvimento, as recentes traduções da Teoria Histórico-Cultural, entre outras.

Este artigo busca revisitar os caminhos percorridos por esse campo de estudos no Brasil, sem perder o lastro com outras regiões do mundo. Para isso, faz uma análise dos primeiros textos organizados e publicados em nosso território, buscando evidenciar seus principais traços e diferenças. Em seguida, percorre os conceitos atualizando e contemporaneizando o debate, além de explicitar os desdobramentos por diversos segmentos, desde os acadêmicos aos espaços escolares. Pretendemos, com isso, que o leitor não apenas conheça a sistematização da Geografia da Infância no país, mas também as fundamentações teóricas que fazem parte desses estudos.

A investigação que abre este texto será o mote em torno do qual parte dos argumentos será escrita, por isso ela estará presente em diversos momentos das linhas que tecem estas páginas. 
A nota de campo inicial mostra a complexidade que pode ser compreender as crianças e cada uma das infâncias que se tecem com suas geografias. Algumas vezes, pode-se parecer um estrangeiro ante o desafio que se cria nas vivências das pesquisas com crianças e mesmo na relação que temos com elas no cotidiano institucional e em diversos espaços. Contudo, nesse tecido é que vão se consolidando os estudos da infância e suas Geografias.

A Geografia da Infância, seus fundamentos, seus estudos, os textos, os argumentos e tudo mais que concorre para sua existência no território brasileiro são os desafios deste artigo.

\section{No começo... a infância, as crianças e seus espaços}

Ao privilegiar o espaço físico-social (não é mais possível dicotomizar estes dois termos, sendo o hífen sinal de uma imbricação e não de uma disjunção) na abordagem da infância a partir de si mesma, e ao adoptar como constructos expressões como território e territorialidade, espaço e lugar, (...) apresenta-se um significativo contributo para a inteligibilidade do modo como o habitus se funde com o habitat e vice-versa, e como tudo isto se configura em trajectos e processos de identificação infantil. (Sarmento, 2005 apud Lopes; Vasconcellos, 2005: 33)

O primeiro livro lançado no Brasil, que buscou abordar, de forma direta, o tema da Geografia da Infância, foi publicado no ano de 2005, sendo intitulado "Geografia da Infância - reflexões sobre uma área de pesquisa", de Jader Janer Moreira Lopes e Tânia de Vasconcellos.

A obra é dividida em capítulos assim descritos: "Introdução, Geografia da Infância: emergindo o tema; Geografia da Infância: desenhando conceitos; Geografia da Infância e croquis territoriais: narrando experiências em pesquisa qualitativa com crianças e Geografia da Infância, territórios infantis e contemporaneidade: outras reflexões". Conta com uma apresentação assinada por Vera Vasconcellos e um prefácio assinado por Manuel Jacinto Sarmento, ambos pesquisadores envolvidos no trabalho com crianças.

A arquitetônica do livro e do sumário desenha alguns conceitos centrais que os autores traçam como base da Geografia da Infância, algo que irá aparecer explicitamente no corpo da obra, como pode ser percebido no trecho a seguir: 
Assim toda criança é criança de um local; de forma correspondente, para cada criança do local existe também um lugar de criança, um lugar designado pelo mundo adulto e que configuram os limites da sua vivência; ao mesmo tempo toda criança é criança em alguns locais dentro do local, pois esse mesmo mundo adulto destina diferentes parcelas do espaço físico para a materialização de suas infâncias. (Lopes; Vasconcellos, 2005: 39)

No texto, o protagonismo infantil frente ao espaço vivido já é evocado:

As crianças, ao apropriarem-se desses espaços e lugares, reconfiguram-nos, reconstroem-nos e, além disso, apropriam-se de outros, criando suas territorialidades, seus territórios usados. A isso chamamos de territorialidades de crianças, das geografias construídas pelas crianças. (Lopes; Vasconcellos, 2005: 39)

Nesta e em outras passagens da obra, torna-se explícito o princípio central em torno do qual os argumentos são construídos: a afirmação de que toda vivência humana, incluindo a das crianças, ocorre em um espaço. O ser e o estar no mundo de todas as pessoas, além de estarem situados também em um tempo, também são marcados pelo espaço, evidenciando que todas as ações apresentam sempre uma dimensão histórica e outra geográfica, sendo essa condição geo-histórica que permite a constituição da Geografia da Infância.

A Geografia da Infância, segundo Lopes (2018), compor-se-ia por dois caminhos: compreender as crianças, suas infâncias através do espaço geográfico e das expressões espaciais que dele se desdobram, como a paisagem, o território, o lugar, as redes, as regiões (entre outros), além do desejo de compreender as geografias das crianças. Reconhece-se, assim, que as crianças possuem uma linguagem espacial, uma memória espacial, uma vivência espacial, sendo a atividade criadora das crianças também uma atividade espacial.

Tabet (2013), ao fazer a abordagem do campo de estudos da infância de língua inglesa, afirma que, entre esses autores, os termos "geography of children" e "children's geography" são mais usados comumente, diferenciando-se, portanto, da expressão cunhada no Brasil. Lopes (2018) assinala que, quando foi organizada a primeira publicação, a opção de utilizar o termo "Geografia da Infância" e não "Geografia das Crianças", presente nos trabalhos ingleses, deveu-se ao fato de reconhecerem o vocábulo "infância” como uma expressão em torno da qual ocorrem disputas dos diferentes setores da sociedade, processo em que inclusive as crianças estariam contempladas. Declara-se, assim, a demarcação entre crianças e infâncias e todas as suas aproximações e reconhece-se o caráter histórico, social e geográfico desse último, como um arranjo em constantes mudanças e 
transformações, cujas universalidades não estariam fora do fazer hegemônico que, tradicionalmente, se busca e das relações que se estabelecem entre saberes e poderes, das circunstâncias que tornam todas as palavras uma constante arena (Bakhtin, obras diversas). Voltemos a Lopes e Vasconcellos (2015: 23):

(...) a mesma noção de infância apresenta diferentes apropriações de acordo com os interesses de quem as utiliza, e a sua pretensa universalidade só existe quando necessária. Dessa forma, os feixes que definem o sentido de infância variam de acordo com os interesses destinados pela sociedade às suas diferentes camadas sociais, estabelecendo diferentes caminhos para a vida adulta.

Devemos considerar que "existem certos termos que transitam cotidianamente entre nós, e seu uso contínuo nos leva a esquecer que as palavras se fazem, se constroem, se transformam, na cultura e na história..." (Meyer; Lopes; Vasconcellos, 2012: 3). Não é diferente para o caso da infância e ao assumir a geograficidade como uma das marcas desse processo, evoca-se um dos princípios geográficos, o do posicionamento e da localização, que circunscreve os eventos, as pessoas e, nesse caso, crianças em fronteiras territoriais, que também são fronteiras de sua corporeidade. $\mathrm{O}$ nascimento humano ocorre sempre em determinados locais, de onde emerge a história individual e coletiva, embaçando limites, divisas, encontros, centralidades, confins e outros atributos geográficos que compõem a existência de todos nós. As memórias de Pantevis (2018), e sua infância passada na Colômbia é carregada de conflitos armados, da presença da guerra, nos anos de 1980:

Lembro de muitas coisas daquela época [infância]. Lembro de um dia que minha mãe chorava por culpa de meu padrasto que não tinha chegado em casa, era como oito horas da noite e ele ainda não chegava, lembro dessa hora porque já tínhamos jantado e ela chorava muito porque ele ainda estava na rua. Nessa hora começou um barulho de tiros de armas de fogo, minha mãe sabia que era a guerrilha que estava chegando de novo na cidade. Ela começou a rezar, a gente foi para parte atrás da casa, especificamente no banheiro, fomos para nos proteger e ficamos a noite inteira aí porque tínhamos muito, muito medo de sermos atingidos por um tiro perdido. Minha mãe achava que nessa noite iam matar meu padrasto por ficar na rua.

Por enquanto, a gente se escondia no banheiro da casa, ela me pedia para não fazer barulho, eu não consegui entender muito bem a situação nesse momento até que eu fiquei dormindo em um colchão que ela levou para o banheiro (...) (Pantevis, 2018: 28, tradução nossa). 
A Geografia da Infância situar-se-ia, nessa interface, entre temas que são caros à própria ciência geográfica, entre os quais destacamos a noção de paisagem, de território, lugar e outros aqui já expressos. Esses temas se relacionam com a infância, com as autorias e lógicas infantis frente aos seus espaços vividos, revelando um protagonismo das crianças que se constrói em estreitas fronteiras com o mundo social, com o mundo adulto e entre as próprias crianças.

Outro texto que teve grande importância no movimento dessa área no Brasil foi a publicação "Geografia da Infância: contribuições aos estudos das crianças e suas infâncias". Nesse artigo, Lopes (2013) faz um registro dos principais autores e postulados que influenciariam os estudos envolvendo os liames entre crianças e espaço geográfico. Os anos 70, no século XX, seriam o marco temporal em que se situaria a produção sistemática desses trabalhos, marcados pela sistematização da Geografia Humanista como uma nova linha de pensamento dentro da própria ciência geográfica. Essa linha emerge fazendo "críticas aos estudos estatísticos na Geografia, à descrição racionalista do positivismo e ao reducionismo economicista do movimento marxista dentro dessa ciência" (Lopes, 2013: 285).

Ao buscar compreender a "percepção e representação do espaço por indivíduos, entendendo seu caráter único, singular, ao mesmo tempo em que reconhece o seu pertencimento e compartilhamento a um determinado grupo cultural" (Lopes, 2013: 285), algumas obras terão grande influência no desenho da Geografia da Infância: os estudos de Tuan (1980) sobre espaço e lugar (publicado inicialmente no livro Topofilia); de Piaget (obras diversas, mas pode-se marcar, sobretudo, a escrita em conjunto com Inhelder, intitulada "A representação do espaço na criança"); a noção de espaço vivido organizada por Frémont (1980) e publicada na obra "La Région, espace vécu” (A região, espaço vivido); além do livro "A Imagem da Cidade", de Kevin Lynch (1960).

Merece ser ressaltado que, na mesma revista, Lopes e Fichtner (2017), no artigo "O espaço de vida da criança: contribuições dos estudos de Marta Muchow às crianças e suas espacialidades”, manifestam os estudos dessa investigadora alemã, em torno dos anos 30 do século XX, como uma das primeiras pesquisas que tratará das crianças e seus espaços. Ao final do texto, esses autores afiançam que, em relação aos achados de campo de Muchow (2012), suas afirmativas "poderiam estar presentes em qualquer obra atual que preconiza sobre o protagonismo e a participação das crianças, suas lógicas e formas próprias de ser e estar no espaço" (Lopes; Fichtner, 2017: 773), ainda que trabalhos "posteriores, que tiveram grande impacto nos estudos da percepção espacial e ambiental, acabaram se tornando mais conhecidos" (idem), muitas dessas ideias já "haviam sido esboçadas por Muchow anos antes" (idem). 
Buscando atualizar a produção sobre a Geografia da Infância no país, Lopes e Costa (2017) explicitam um quadro de diversos trabalhos referenciados nessa área. Procedendo a uma categorização dos assuntos que marcam os estudos, reconhecem sete possíveis agrupamentos: Crianças e Espacialidades; Geografia da Infância e Tecnologias; Diálogos entre a Geografia da Infância, geografia e demais saberes escolares; Geografia da Infância e form(ação) docente; Geografia da Infância e Cartografia com crianças; Geografia da Infância e pesquisa com bebês e Geografia da Infância e temáticas diversas.

No primeiro se encontrariam os trabalhos que "trazem em comum a reflexão sobre a autoria das crianças na produção de suas Geografias. Nesse sentido, mantêm o foco nos diferentes usos e apropriações que fazem do espaço, produzindo espacialidades outras" (Lopes; Fichtner, 2017: 112); no segundo, os trabalhos que têm "em comum a presença das tecnologias como elemento constituinte dos espaços vivenciados pelas crianças, buscam compreender as interpretações que elas produzem sobre os usos que fazem de tais espaços, a partir de elementos tecnológicos, na relação com os adultos e com seus pares" (ibidem: 113); no terceiro, "as pesquisas discutem como o trabalho que envolve o saber geográfico escolar é tocado pelas Geografias que as crianças produzem e das quais são portadoras" (ibidem: 114); no quarto, temos trabalhos cujo foco principal situariam "aspectos formativos e na prática cotidiana do professor em diálogo com as reflexões sobre as crianças e suas geografias" (idem); no quinto, estão as vertentes que marcam "as crianças pelo seu protagonismo. Por isso, falam de uma cartografia COM crianças, e não PARA ou SOBRE elas" (ibidem: 115); no sexto, as "investigações que trazem como foco principal os bebês e suas espacialidades abrem, ao campo de Estudos da Infância, novas possibilidades de compreensão desses sujeitos cuja dinâmica é pouco conhecida ainda" (idem) e, por último, a "vertente comporta uma diversidade maior de temáticas. São trabalhos que reforçam a importância da Geografia da Infância como referencial que traz como uma de suas principais características as múltiplas possibilidades interpretativas e de diálogo" (idem).

Como se pode perceber, os estudos sobre Geografia da Infância ou temas que tangenciam seus fundamentos vêm se ampliando no Brasil, tornando essa área sólida e sistematizando conceitos e argumentos até então pouco presentes no repertório acadêmico brasileiro. Terminologias como Paisagens da Infância, Territórios de Infâncias, Lugares de Crianças, Crianças Situadas e outras têm sido expressões presentes em muitos trabalhos que encontramos, tecendo possibilidades outras de olhar para as crianças e suas vidas. 


\section{Geografia da Infância: contemporaneizando os argumentos}

O conflito armado colombiano que eu vivi na minha infância, numa cidade que era atingida frequentemente pela guerrilha, era reelaborado em nossas brincadeiras, nos dividíamos em dois grupos de crianças um, representava a guerrilha e o outro a polícia ou o exército. Fazíamos armas improvisadas com paus e fingíamos um enfrentamento entre os dois grupos.

A ideia era matar ao inimigo e para isso tínhamos que gritar "eu matei ele". Quando achávamos o inimigo desatento, o som das armas era simulado por nossas vozes, aqueles sons eram ouvidos na televisão ou nosso cotidiano por alguma vez que a guerrilha atingiu nossa cidade. (Pantevis, 2018: 27, tradução nossa)

A Geografia da Infância, ao assumir a espacialidade das crianças e declarar que todos nós habitamos um espaço geográfico (e somos habitados por ele), também nos lembra de que muitos de nós somos cegos à existência desses espaços em nossas vidas, mas as crianças não! Elas sempre nos recordam, quer em suas ações nas paisagens edificadas, quer em suas linguagens outras, essa condição geográfica em que residimos e que nos residem. Recuperemos um relato expresso em Muchow (2012), no qual a autora alemã fez intensas observações de crianças em uma doca de carregamento, localizada ao noroeste do distrito de Bamberk e que se estende cerca de 80 metros paralelos ao Canal Osterbeck, entre o Canal e a estrada Osterbeck. Entre seus diversos registros, destacamos:

Uma primeira diferença está na perspectiva do que define o próprio local: para os construtores do lugar, para os adultos que utilizam o espaço em sua funcionalidade, o centro focal daquele espaço é na parte baixa, próximo à borda da água; para as crianças, o seu encantamento começa com a periferia do espaço e define-se com uma cerca de madeira de, aproximadamente, 1,5 metros de altura, que envolve o local. A cerca no mundo adulto possui duas funções: definir a fronteira entre a rua e o local, funcionando como um parapeito que protege os transeuntes de cair, ou seja, é um impedidor do movimento e tem como definidor perceptivo principal um sinal ótico; para as crianças, a cerca, por sua vez, é um marcador tátil, pois essas logo buscam entrar em contato com ela, deixando de ser um inibidor do movimento, para se transformar em objeto de ação. Assim, o espaço de vida da criança: contato, a experiência tátil é o que prevalece: toques, escaladas, mãos deslizantes estão sempre presentes. A cerca, no mundo adulto, para e direciona o movimento; no mundo das crianças, é um convite para seu agir. (Muchow, 2012: 14) 
As crianças nos lembram de que toda ação é sempre uma convivência. Por isso, o espaço geográfico nunca é um mero palco por onde estamos apenas passando, mas são intensas possibilidades de desenvolvimento e transformação. A Geografia da Infância, além de "ler" a infância através do espaço geográfico e de suas expressões, busca também o reconhecimento de que as crianças apresentam seus protagonismos geográficos, na interface dos mundos infantis e adultos.

Tudo isso é a Geografia da Infância: os fios entre as crianças, os adultos, as ações sociais, culturais, econômicas, políticas, compostas pelas dimensões de gênero, de classes econômicas e muitas outras e, por essa razão, não podem ser invisibilizadas. Nascer aqui ou acolá faz toda diferença nas infâncias das crianças! Todas as crianças são situadas. Toda vida está localizada e faz parte de uma rede geográfica que não pode ser esquecida.

Essa relação das crianças com suas geografias aparece em muitos vestígios da vida que vão de uma lógica adulta que vem sendo reelaborada pelas crianças, permitindo se definir como uma lógica infantil, como a reelaboração do conflito armado em uma brincadeira, a compreensão das crianças de uma pessoa que vem de outro país, cuja fala é diferente, reelaborando-a como um extraterrestre. Retornamos ao trabalho que abriu este artigo:

A professora põe o mapa no chão para poder conferir de onde a gente é. As crianças estão muitos emocionadas olhando quão grande é o mundo e localizam a Colômbia e o Brasil. As crianças querem desenhar o mundo, a professora entrega folhas brancas e lápis de cor para desenhar.

Umas das crianças [Pierre, 5 anos de idade] me mostra o mapa que ele desenhou. Eu peço para ele me explicar o mapa:

- Pierre: América, Estados Unidos é amarelo. Tem coisas muito legais. Você conhece não?

- Math: não e você?

- Pierre: conheço. Eu conheço, é muito legal. O sul fica muito longe da terra. $\mathrm{O}$ verde é Brasil.

- Math: é mesmo?

- Pierre: é, o mundo inteiro e a floresta. As cores são porque fica mais bonito. Vermelho é a Colômbia, é rosa para ficar mais bonita.

- Math: esse azul, aqui embaixo?

- Pierre: esses dois aqui? Já te falei. Esse é Japão.

- Math: mas, tem vários azuis aqui...

- Pierre: esses dois daqui são Japão mesmo. Porque fala diferente. Esse fala inglês de onde é você. $\mathrm{O}$ outro azul fala japonês mesmo. É porque fala diferente. (Nota de campo $n^{\circ} 3,29$ de setembro de 2016) 
Figura 1 - Desenho produzido por Pierre em sala de aula

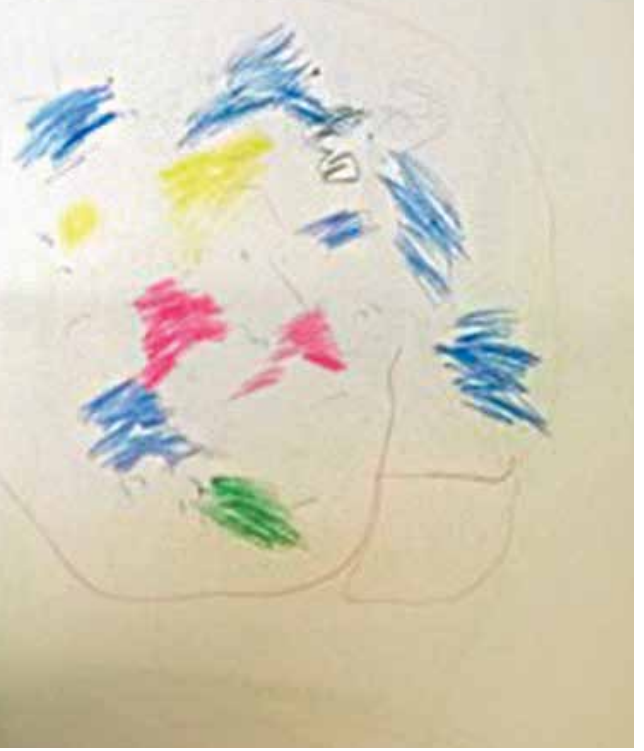

Ainda que as crianças, por séculos, tenham sido isoladas da sociedade, tenham tido sua "infância separada, cativa, encerrada, uma infância acompanhada, defendida, uma infância que não pode explorar, descobrir, maravilhar-se" (Tonucci, 2004: 33), ainda assim, as crianças criam o mundo, um mundo outro, diverso deste que muitas vezes tenta apagá-las.

É assim que o espaço se compõe, como uma categoria da existência e da experiência humana, também nas vivências infantis. Crianças e adultos habitam territórios, paisagens, lugares e estabelecem constantes redes a partir de si e dos outros. Muitas vezes, nós, adultos, abandonados pela infância, somos cegos nessas geografias:

Em uma atividade proposta, que consistia em revisar o mapa e localizar o lugar de origem das personagens dos contos narrados na aula (O menino esperto e Les Petites Crapules de Thomas Sympa), se apresenta a seguinte conversação:

- Eu: você conhece isto aqui? (Mostrando para eles o mapa)

- Maria Fernanda: sim, eu conheço sim, é o mundo todo.

- Eu: pensei que você não sabia... (fico com cara de pensativo)

- Maria Fernanda: (ela pensa e me mostra no mapa) é aí onde eu moro, no Brasil mesmo. 
- Eu: é mesmo, sabia não.

- Maria Fernanda: sim, eu moro aqui, Brasil é perto da escola, o Brasil é Juiz de Fora. (Nota de campo $n^{\circ} .31,18$ de agosto de 2016)

Reconhecemos o espaço infantil como um espaço simbólico, que se aproxima da definição de território cunhada por Haesbaert \& Limonad (2007) que vai desde uma construção histórica e social, que se dá a partir das relações de poder, até a estrutura simbólica que envolve a sociedade e o espaço geográfico. A ele juntamos a experiência na paisagem em toda sua plenitude, envolvendo as formas expressas por Santos (1999), mas também as sensações e as emoções que permitem singularizar nossa existência e a criação de lugares marcados por intensos afetos. $\mathrm{O}$ espaço das crianças, suas geografias, estariam comportados na escuta sensível (Barbier, 1997), ancorados no respeito ao outro, no encontro e no espaço que as crianças têm reelaborado e criado, como inventores de histórias e geografias da vida humana.

Essas descrições trazidas por Pantevis (2018), além de outras delas evidenciam as aproximações de infância, das crianças com seus locais de vivência. A singularidade (ou quem sabe a tragédia) humana é que nenhuma palavra tolera por completo a vida que se vive. Por isso, bem lembrou Bakhitn (obras diversas), não temos álibi em nossa existência no mundo, qualquer enunciação é sempre uma escolha. A gênese da palavra já marca nossa autoria no mundo e isso não é diferente na vida das crianças.

O mesmo pode ser dito do espaço geográfico. Qualquer descrição, por si só, já é uma interpretação do mundo. A palavra adjetiva o espaço. A vida no espaço cria as palavras e também as pessoas. Como nenhuma palavra humana porta a densidade da vida, sua complexidade, diferenças e diversidades, qualquer palavra narrada, além de ser sempre uma escolha prévia, coloca na fronteira a responsabilidade ética para com o outro. Foi Vigotski (2010: 25) que nos lembrou de algo muito especial: "Em forma geral: a relação entre as funções psicológicas superiores foi outrora relação real entre pessoas. Eu me relaciono comigo tal como as pessoas relacionaram-se comigo" (Puzirei, 2000: 25) ${ }^{5}$. Somos sujeitos de linguagem, forjados nas palavras outras (Bakhtin, obras diversas), nas linguagens de espaços e tempos, cronotopias arroladas às vivências, que nos singularizam em nossa ontogênese ${ }^{6}$. Assim, toda criança é enunciação, toda criança é autora.

5 PUZIREI, A. A. Lev. S. Vigotski: Manuscrito de 1929. Educação \& Sociedade, Campinas, ano XXI, nº 71, p. 21-44, jul., 2000. Disponível em: <http://www.scielo.br/pdf/es/v21n71/a02v2171.pdf.> Acesso em: 08 nov. 2018.

6 Ontogênese refere-se ao desenvolvimento de um indivíduo dentro da própria espécie. Por exemplo: como, ao nascer, um bebê humano se desenvolve, por quais momentos ele passa em seu processo de humanização. 
A infância faz-se de forma intensa, em que paisagens (na sua totalidade), territórios, lugares e muitas expressões do espaço geográfico se forjaram, são forjados, documentam o corpo externo e interno, criam nossa unidade com o mundo. Por isso, podemos falar em uma Geografia da Infância, uma vez que não existe vida humana fora do espaço, assim como também não existe fora do tempo. Se o ser e estar das crianças são uma ação temporal, ela é sempre espacial.

Segundo Vigotski (2010), isso é a vivência e, de acordo com Bakhtin (2014), isso é cronotopia. Escutemos as palavras desses autores. Para Vigotski (2010: 683-684):

De forma mais precisa, mais exata, o que nós podemos dizer a respeito dos exemplos que vimos quando discutimos as crianças é que os elementos existentes para determinar a influência do meio no desenvolvimento psicológico, no desenvolvimento de sua personalidade consciente é a vivência. A vivência de uma situação qualquer, a vivência de um componente qualquer do meio determina qual influência essa situação ou esse meio exercerá na criança. Dessa forma, não é esse ou aquele elemento tomado independentemente da criança, mas, sim, o elemento interpretado pela vivência da criança que pode determinar sua influência no decorrer de seu desenvolvimento futuro.

E ele continua:

(...) na vivência, nós sempre lidamos com a união indivisível das particularidades da personalidade e das particularidades da situação representada na vivência. Por isso, parece apropriado conduzir de maneira sistemática a análise do papel do meio no desenvolvimento da criança, conduzi-la do ponto de vista das vivências da criança, porque na vivência, como já coloquei, são levadas em conta todas as particularidades que participaram da determinação de sua atitude frente a uma dada situação. Por exemplo, será que todas as minhas peculiaridades constitutivas, dos mais diversos tipos, participam inteiramente e também em bases iguais de todas as situações? Claro que não. Em certa situação, algumas de minhas particularidades constitutivas desempenham papel principal, em outra, outras desempenham o papel principal, enquanto, no primeiro caso, elas podem estar absolutamente ausentes. Para nós é importante saber, não de maneira geral, quais são as peculiaridades da criança, mas é importante saber quais dessas peculiaridades constitutivas desempenharam um papel determinante para definir a atitude da criança frente a uma dada situação, enquanto em outra situação, outras particularidades constitucionais desempenharam seu papel. 
Para Bakhtin (2014: 211): "À interligação fundamental das relações temporais e espaciais, artisticamente assimiladas em literatura, chamaremos cronotopo (que significa "tempo-espaço") [...] nele é importante a expressão de indissolubilidade de espaço e de tempo".

Vigostki e Bakhtin buscaram trazer de volta a dimensão espacial do ser humano perdida na modernidade. A modernidade ocidental privilegiou o tempo em detrimento do espaço. Temporalizou o humano em uma lógica cronológica e linear expressa em muitas dimensões da vida humana (no cotidiano, nas instituições, na ciência, no nosso imaginário individual e coletivo), mas encobriu a espacialidade como uma faceta fundamental da ontologia humana e, claro, da própria epistemologia, já que ambas habitam nossa existência.

Massey (2008: 31), ao conceituar espaço, afirma que este é a esfera da possibilidade da existência da multiplicidade "[...] onde distintas trajetórias coexistem, é a esfera da possibilidade da existência de mais de uma voz". Para ela, "sem espaço não há multiplicidade, sem multiplicidade não há espaço. Multiplicidade e espaço são co-constitutivos." Declara ainda: "precisamente porque o espaço é o produto de relações-entre-relações, que são práticas materiais necessariamente embutidas que precisam ser efetivadas, ela está sempre num processo de devir, está sempre sendo feito - nunca finalizado, nunca se encontra fechado." Assim como a vida humana e seu constante inacabamento!

Falar em Geografia da Infância é isso. É ver, no espaço geográfico, a vivência das crianças, é ler a infância e os indícios de como as crianças estão na sociedade a partir da paisagem, dos territórios, das redes que se estabelecem, dos lugares que se cunham. Por isso, qualquer infância é espacializada, qualquer criança vive em um espaço, tendo aí atividade criadora de si e do mundo. Por isso, posso falar em infância, em geografias da infância, trazendo as crianças, suas potentes linguagens e suas possibilidades de compartilhar a existência com o outro. $\mathrm{O}$ nascimento de um bebê é um encontro geracional, é o primado de sua caminhada no mundo, na interface das histórias daqueles que já o habitam, é, por si, também um ato geográfico.

\section{Considerações finais}

Continuando atividade dos mapas, revisando o mapa-múndi, as crianças se sentem emocionados de ver tantas coisas, tantas cores e de que a professora mostre para eles diferentes países:

- Patrícia: esse aqui é o Brasil, vocês conhecem. 
- Maria Fernanda: eu moro no Brasil, Brasil é muito perto da escola, o Brasil é Juiz de Fora.

- Eu: como assim?

- Maria Fernanda: como assim o quê? (Com cara de preocupação olha para mim e outra criança intervém na conversa).

- Pierre: lembra que ela falou que é no Brasil onde ela mora, também eu, é aí onde eu moro, muito perto da escola. Olha aí (me mostra no mapa) esse aqui, esse pequenininho é o Brasil, você não sabe de nada.

- Milena: eu também moro aí e também viajei para outro país, viajei para o Rio de Janeiro.

- Maria Fernanda: sim, mas essa aqui é a escola, a gente não pode sair daqui, só quando os pais vêm pegar a gente.

(Todas as crianças se espalham pela sala). (Nota de campo $n^{\circ} 34,8$ de setembro de 2016)

Buscamos, neste artigo, evidenciar para o leitor os caminhos que vem trilhando a Geografia da Infância em território brasileiro. Para isso, dialogamos com algumas obras que, para nós, tiveram significativa importância na estruturação dessa área e que vêm influenciando diversos trabalhos.

Marcamos também alguns conceitos-chave que fazem parte desses estudos e que se estabelecem na fronteira com a própria ciência geográfica. Vale destacar que muitos desses estudos tiveram sua gênese na área da Educação e em outras, como a Psicologia, por exemplo, mas como parte de um arcabouço mais amplo: o do campo de Estudos da Infância. A Geografia acadêmica só recentemente vem se apropriando e dialogando com os recentes postulados que envolvem as investigações da infância. Com isso, tem passado a olhar as crianças de outra forma, indo além dos dados estatísticos (como taxa de natalidade e mortalidade infantis) e da dimensão cognitiva que têm sido priorizados em muitos trabalhos.

Tentamos também marcar a necessidade de se escutar sensivelmente as crianças para ouvirmos, vermos, sentirmos suas vivências espaciais, suas culturas geográficas, aprendendo constantemente com elas e em suas existências singulares. Como postulou Couto ao trazer a diversidade e diferenças presentes no continente africano: "Nessas regiões encontro gente que não sabe ler livros. Mas que sabe ler seu mundo. Nesse universo de outros saberes, sou eu o analfabeto" (Couto, 2011: 14).

$\mathrm{O}$ apontamento de Couto abrange a relação da pessoa com o meio, em uma relação de alteridade, na vivência no mundo e como ele faz para situar-se nele, em seu lugar, em sua topofilia (Tuan, 1980), criando um espaço com o qual 
convivo, deixo de sentir dúvidas, não me sinto alheio, abandonando as incertezas, tão manifestadas em Galeano (2002: 87):

No café da manhã, minhas certezas servem-se de dúvidas. E têm dias em que me sinto estrangeiro em Montevidéu e em qualquer outra parte. Nesses dias, dias sem sol, noites sem lua, nenhum lugar é o meu lugar e não consigo me reconhecer em nada, em ninguém. As palavras não se parecem àquilo que dão nome, e não se parecem nem mesmo ao seu próprio som. Então não estou onde estou. Deixo meu corpo e saio, para longe, para lugar nenhum, e não quero estar com ninguém, nem mesmo comigo, e não tenho, nem quero ter, nome algum: então perco a vontade de me chamar ou de ser chamado.

Esses chamamentos dos outros vão provocando identidades/alteridades que fazem com que nos sintamos próximos às nossas geografias, criando intimidades evocadas na fronteira da sociedade. Não é um espaço íntimo no sentido de isolado, mas é um viver que se faz na constância com o outro. Acolhimentos! García Márquez narra a cidade de Macondo como uma cidade simples, sem nada, mas onde acontecia tudo:

Macondo era então uma aldeia de vinte casas de barro e taquara, construídas à margem de um rio de águas diáfanas que se precipitavam por um leito de pedras polidas, brancas e enormes como ovos pré-históricos. O mundo era tão recente que muitas coisas careciam de nome e para mencioná-las se precisava apontar com o dedo. [...] (García Márquez, 2003: 7)

Ou como escreveria Guimarães Rosa (2001: 506) em Grande Sertão Veredas: "O sertão aceita todos os nomes: aqui é o Gerais, lá é o Chapadão, lá acolá é a caatinga". Desse jeito são os territórios, as paisagens, os espaços e os lugares, são linguagens humanas, narrativas das crianças, dos adultos e relações que se transformam ou reelaboram, de onde é possível gestar o "novo eu". Nas palavras de Jerebtsov (2014; 20): "Em atividade conjunta, na cooperação, na co-existência, em con-vivência, nasce o novo Eu. E esse novo Eu exige vivências para a elaboração de determinações, adaptações para o Eu renovado".

Nessa perspectiva, o espaço geográfico forja-se na sua dimensão física e semiótica, em explosões axiológicas, em que eu posso viver através desse outro que me dá vida, que me leva. Segundo Pantevis (2018: 194):

E aí vem na minha mente cada momento durante toda essa vivência (4 anos com as crianças) toda minha vida tentei existir para esse outro, em um grito desesperado para poder existir, sempre estive entre vozes e entre vocês em 
busca de assumir essa cultura e foram as crianças nesta pesquisa que me mostram essa cultura única que criamos em nossa convivência e que eles são autores dessa cultura (Tradução nossa).

Tudo isso é pura Geografia. Geografia de uma criança, hoje adulto, mas que reconhece as infâncias que me acompanham por toda vida. As várias vozes que me formaram. Imortalidades! Além da receita, trago Adélia Prado (1993: 11), outra mineira, que faz questão de afirmar:

Quando nasci um anjo esbelto, desses que tocam trombeta, anunciou: vai carregar bandeira Cargo muito pesado pra mulher, esta espécie ainda envergonhada. Aceito os subterfúgios que me cabem, sem precisar mentir.

Não sou tão feia que não possa casar, acho o Rio de Janeiro uma beleza e ora sim, ora não, creio em parto sem dor.

Mas o que sinto escrevo. Cumpro a sina. Inauguro linhagens, fundo reinos

-- dor não é amargura.

Minha tristeza não tem pedigree, já a minha vontade de alegria, sua raiz vai ao meu mil avô.

Vai ser coxo na vida é maldição pra homem Mulher é desdobrável. Eu sou.

Que possamos ser desdobráveis em nossas vivências, em nossas cronotopias, em nossas geografias de nossas infâncias! Criancices também fomentam e forjam a história humana, salvam-nos de nossas rotinas e repetibilidades, proclamando o novo, o inexistente, colocando-nos sempre em um ponto no espaço para além de nós mesmos, quebram nossa fixidez. Revertem-nos em caminhantes! Vida crianceira!

\section{Referências}

BAKHTIN, Mikhail. Para uma filosofia do ato responsável. São Carlos, SP: Pedro \& João Editores, 2014. 
BARBIER René., Lapproche transversale, l'écoute sensible en sciences humaines, Paris: Anthropos, coll. Exploration interculturelle, 1997, 357 p.

COUTO, Mia. E se Obama fosse Africano? E outras intervenções. São Paulo: Companhia das Letras, 2011.

FRÉMONT, Armand. A região, espaço vivido. Coimbra: Almedina, 1980.

GALEANO, Eduardo. O livro dos abraços. Tradução de Eric Nepomuceno. Porto Alegre: L\&PM, 2002. Disponível em: <http://delubio.com.br/biblioteca/wp-content/uploads/2014/03/O-Livro-dos-Abrac_os-Eduardo-Galeano.pdf $>$. Acesso em: o8 jul. 2018.

GARCÍA MARQUEZ, Gabriel. Cem Anos de Solidão. Trad. Eliane Zagury. Rio de Janeiro: O Globo; São Paulo: Folha de São Paulo, 2003.

HAESBAERT, Rogério; LIMONAD, Ester. O território em tempos de flobalização. Etc., espaço, tempo e crítica, v. 1, n. 2, Rio de Janeiro, ago. 2007, p. 39-52. Disponível em: $<$ http://www.uff.br/etc/UPLOADs/etc\%202007_2_4.pdf.>. Acesso em: 08 jul. 2018.

JEREBTSOV, Serguei. Gomel a cidade de L.S. Vigotski. Pesquisas científicas contemporâneas sobre instrução no âmbito da Teoria Histórico-Cultural de L.S. Vigotski. VERESK - Cadernos Acadêmicos Internacionais. Brasília: UniCEUB, v.1, p. 7 27, 2014. Disponível em: <http://www.repositorio.uniceub.br/bitstream/235/5750/6/ VERESK.pdf $>$. Acesso em: 08 jul. 2018.

LYNCH, Kevin. The Image of the City. Cambridge: M. I. T. Press, 1960.

LOPES, Jader Janer Moreira. Geografia da Infância: contribuições aos estudos das crianças e suas infâncias. Revista Educação Pública, v. 22, n. 49/1, 2013. Disponível em: <HTTP://PERIODICOSCIENTIFICOS.UFMT.BR/OJS/INDEX.PHP/EDUCACAOPUBLICA/ARTICLE/VIEW/915>. Acesso em: 08 jul. 2018.

. Notas da palestra: Geografia da Infância: percursos históricos e geográficos no Brasil e no mundo. I Colóquio Internacional Crianças e Territórios de Infância no Brasil. 26 e 28 de março de 2018. UNB: Brasília.

LOPES, Jader Janer Moreira.; VASCONCELLOS, Tania. Geografia da infância: reflexões sobre uma área de pesquisa. Juiz de Fora: Feme, 2005. 10op.

LOPES, Jader Janer Moreira.; FICHTNER, Bernhard. O espaço de vida da criança: contribuições dos estudos de Marta Muchow às crianças e suas espacialidades. Revista Educação Pública, v. 26, n. 63, 2017. Disponível em: <http://periodicoscientificos.ufmt.br/ojs/index.php/educacaopublica/article/view/5564>. Acesso em: 08 nov. 2018.

LOPES, Jader Janer Moreira.; COSTA, Bruno Muniz Figueiredo. Geografia da infância: onde encontramos as crianças? Acta Geográfica, Boa Vista, Edição Especial 2017, p. 101-118. Disponível em: <https://revista.ufrr.br/actageo/article/view/4774>. Acesso em: 08 jul. 2018. 
MASSEY, Doreen. Pelo espaço: uma nova política da espacialidade. Rio de Janeiro: Bertrand Brasil, 2008. $312 \mathrm{p}$.

MEYER, Angela.; LOPES, Jader Janer Moreira.; VASCONCELLOS, Tania. Infância. Sede de ler: Programa de alfabetização e leitura, Niterói, ano 3, n.3, p.3-4, ISSN 2179-5258, Editora de UFF, 2012.

MUCHOW, H. H. Der Lebensraum des Großtadtkindes. Doutschland: Beltz Juventa, 2012, $212 \mathrm{p}$.

SUAREZ, Mathusalam Pantevis. Coitado menino está doente: Relación de los niños com el ser extranjero. Tese (Doutorado) - Educação, Universidade Federal de Juiz de Fora, Juiz de Fora, 2018.

PIAGET, Jean.; INHELDER, Barbel. A representação do espaço na criança. Porto Alegre: Artes Médicas, 1993.

PRADO, Adelia. Bagagem. São Paulo: Siciliano, 1993.

ROSA, Guimarães. Grande Sertão: Veredas. Rio de Janeiro: Nova Fronteira, 2001.

SAID, Edward. Orientalismo. Trad. María Luisa Fuentes. Barcelona: Liberduplex, S. L. U., 2002.

SANTOS, Milton. A natureza do espaço: espaço e tempo, razão e emoção. São Paulo: Hucitec, 1999, $384 \mathrm{p}$.

SARMENTO, Manuel Jacinto. Prefácio. In: LOPES, Jader Janer Moreira.; VASCONCELLOS, Tania. Geografia da infância: reflexões sobre uma área de pesquisa. Juiz de Fora: Feme, 2005, 100 p.

TEBET, Gabriela Guarnieri De Campos. Isto não é uma criança! Teorias e Métodos para o estudo de bebês nas distintas abordagens da Sociologia da Infância de língua inglesa. Tese de Doutorado, 2013, 154 p. São Carlos: UFSCar. Educação. 2013.

TONUCCI, Francesco. ¿Qué niños? In: ABRIL, P. et al. III Encuentro la Ciudad de los

Niños. ¿Qué ciudades? ¿Qué niños? Madrid: Acción Educativa, 2004.

TUAN, Yi-Fu. Topofilia. São Paulo: Difel, 1980.

VIGOTSKI, Lev Semionovich. Quarta aula: a questão do meio na Pedologia. Tradução de Márcia Pileggi Vinha. Psicologia USP, São Paulo, v. 21, n. 4, p. 681-701, 2010.

Recebido em 23/01/2018

Aprovado em 05/06/2018

\section{Como citar este artigo:}

LOPES, Jader Janer Moreira e SUAREZ, Mathusalam Pantevis. "É de outro planeta, ele é extraterrestre". Revisitando os estudos em Geografia da Infância no Brasil. Contemporânea - Revista de Sociologia da UFSCar, v. 8, n. 2, jul.- dez. 2018, pp. 495-512. 